УДК 94(48)082.94(47)084.5

DOI 10.18413/2687-0967-2020-47-4-933-938

\title{
Практика политического процесса в Сомали
}

\author{
А.В. Орешкина \\ Национальный исследовательский Нижегородский Университет им. Н.И. Лобачевского (ННГУ) \\ Россия, 603950, г. Нижний Новгород, пр. Гагарина, 23 \\ E-mail: oreshkina_nastja@mail.ru
}

\begin{abstract}
Аннотация. Распад государства всегда ведет к гражданской войне, экономическому коллапсу, краху социального обеспечения и т. Д. Государство не может выполнять функцию гаранта безопасности для своих граждан. Политическое участие граждан становится минимальным. На примере Сомали видно, что проведение преобразований в условиях кризиса выливается в усиление конфликтности. Западная псевдодемократия не вплетается в канву межклановой борьбы, в стране нет разных политических взглядов. Национальное самосознание не приемлет компромиссов, «победитель забирает все». Поэтому навязанная метрополиями модель управления государством в итоге вылилась в коррупцию и непотизм в правительстве. Из-за длительного периода колониальной зависимости Сомали в умах народа укоренились ограничение суверенитета и экономическая экспансия. Только традиционные структуры несут ценностные ориентиры для сомалийского общества, которые потенциально могут переродиться в конфедеративную общность или автономные самоуправляемые провинции.
\end{abstract}

Ключевые слова: гражданская война, межклановая борьба, национальное самосознание, ограничение суверенитета, псевдодемократия, непотизм, трайбализм.

Для цитирования: Орешкина А.В. 2020. Практика политического процесса в Сомали. Via in tempore. История. Политология, 47 (4): 933-938. DOI: 10.18413/2687-0967-2020-47-4-933-938.

\section{The practice of political process in Somalia}

\author{
Anastasia V. Oreshkina \\ National research Nizhegorodsky University named after N.I. Lobachevsky (NNGU) \\ 23 Gagarin avenue, Nizhny Novgorod, 603950, Russia \\ E-mail: oreshkina_nastja@mail.ru
}

\begin{abstract}
State collapse always leads to a civil war, economic and welfare crises, etc. The state doesn't secure its citizens anymore. Political activities among people are minimal. As we can see in Somalia any changes in the abovementioned situation empower the conflict. Western pseudo-democracy cannot interact with infighting. The country has no different political opinions. National identity doesn't accept a compromise, «the winner takes it all». Parent states model of country management in Somalia turns into corruption and nepotism in the government. Due to a long-term colonial dependence Somali people connect it with limited sovereignty and economic expansion. Only traditional structures such as clans, secure social values. Potentially they can evolve into confederation or autonomous self-governed provinces.
\end{abstract}

Keywords: civil war, infighting, national identity, limited sovereignty, pseudo-democracy, nepotism, tribalism.

For citation: Oreshkina A.V. 2020. The practice of political process in Somalia. Via in tempore. History and political science, 47 (4): 933-938 (in Russian). DOI: 10.18413/2687-0967-2020-47-4-933-938. 
Хаос, царящий в некоторых государствах современного мира, порождает нестабильную внешнеполитическую обстановку. Это объясняется слабостью правления, нелегитимностью власти и неэффективностью государства как института ${ }^{84}$, в котором «отсутствует реальное воплощение права граждан на участие в политике, равно как и подотчетность лидеров народу» ${ }^{85}$. По словам Р. Ротберга, «ситуация распада государства всегда создается людьми; она не может быть случайностью, не может быть вызвана географическими, экологическими или какими-то внешними факторами. Именно ошибочные решения лидеров стран неразвитого региона разрушают государства и вообще любую, самую слабую форму политического управления, которая остается на руинах государственности» ${ }^{86}$.

Если перед нами государство, находящееся на грани краха, то по образу и подобию раненого зверя его пытаются растерзать другие участники политического процесса. Р. Дорфф утверждает, что в такой ситуации степень бессилия государства не имеет значения, так как суть проблемы одна - слабая законная власть, которая впоследствии приводит к таким последствиям, когда государство гибнет ${ }^{87}$. В итоге страна превращается в «распавшееся государство». В этом случае международную помощь распределяет между собой правящая элита, в след за этим страну покидают иностранные торгово-экономические представительства. Государство начинает экономить, рушится социальный сектор, растет безработица и инфляция. Беспорядок во всех сферах общества знаменуется утратой у людей каких-либо гарантий безопасности в лице государства, произвол во власти провоцирует расхищение имущества и ресурсов. Отменяются выборы, участие граждан в политике сводится к нулю. Такая анархия порождает формирование военных группировок, которые, обладая зарубежной поддержкой, вступают в борьбу за власть. Сомалийский кризис 1990-х - начале 2000-х годов происходил именно по такому сценарию.

В Сомали на лицо полное отсутствие желания у всех территориальных образований объединяться с целью создания единого унитарного государства, поэтому поиск универсального способа разрешения сомалийского кризиса остается открытым. Помимо этого, препятствиями на пути мирного урегулирования в Сомали являются постоянные конфликты между представителями кланов и подкланов, наличие автономных образований (Сомалиленд, Пунтленд), которые не стремятся войти в состав единого государства, и нехватка средств на миростроительство как таковое. С другой стороны, проведение какихлибо реформ в стране может обернуться только усилением конфликта, неуправляемостью политических процессов и гражданской войной, как в Сомали.

Хотя национальное самосознание у сомалийцев было всегда. Чтобы понять это, достаточно посмотреть на сомалийский флаг. На синем фоне (как и на флаге ООН) изображена пятиконечная звезда, лучи которой обозначают Британский Сомалиленд, Итальянский Сомалиленд, сомалийцев, проживающих на территории Кении, Эфиопии и Джибути $^{88}$. Даже глядя на сомалийский флаг, мы понимаем, что сомалийское подсознание воспринимает государственность только в рамках концепции государства-нации.

Однако модель западного образца в данном случае не применима. Так, первый президент Сомали, Аден Абдулла Осман, был прекрасным примером того, как колониальные силы годами взращивали и поддерживали верных себе сторонников. Бывший гражданский служащий времен итальянской колонизации Сомали, представитель суб-клана хавийя.

${ }^{84}$ Ротберг Р.И. Когда государства терпят поражение: причины и последствия. Принстон, НьюДжерси: Принстон Юниверсити Пресс. 2004. С. 5. ISBN-10. 2004.

${ }^{85}$ Патрик С. Слабые государства и мировые угрозы: факты и вымысел? // Вашингтон Квотерли, Т. 2. № 29. 2006 .

${ }^{86}$ Ротберг Р.И. Коррупция, глобальная безопасность и мировой порядок / Под ред. Роберта И. Ротберга. Вашингтон. 2009. С. 47.

${ }^{87}$ Dorff R. Failed States After 9/11: What Did We Know and What Have We Learned? // International Studies Perspectives. № 6. P. 24. 2005.

${ }^{88}$ Contini P. The Somali Republic: An Experiment in Legal Integration. London. 2013. P. 50. 
При нем в течение девяти лет страна жила в относительном мире, поскольку большинство колониальных привилегий было в руках, определенных «излюбленных» кланов, реорганизовывать государственное устройство не было нужды ${ }^{89}$. Президент и его сторонники пытались строить парламентарную демократию, и на выборах 1964 г. принимала участие 21 политическая партия ${ }^{90}$. Однако сомалийское общество было не в силах выработать демократию, основанную на разных политических взглядах каждого клана. Не было противоречащих друг другу идей, так как, по сути, кланы рознит только их происхождение и место дислокации.

Практика политического процесса в Сомали идет по принципу «победитель забирает все». Поэтому война является частью быта сомалийцев наравне с совместным трудом. Суровые климатические условия, выжить при которых можно только вступая в союз, определяют бытие сомалийцев. Культура сомалийцев не приемлет компромисса. У них нет понимания, что слабых надо защищать, поэтому наиболее крупные кланы доминируют ${ }^{91}$. Можно легко провести параллель с США, когда на выборах президента судьбу Джорджа Буша и Альберта Гора решил один единственный штат Флорида ${ }^{92}$.

Коррупция и непотизм - основные черты, которые отличали политическую систему в сомалийском обществе. Корни коррупции крылись в трайбализме, поскольку неквалифицированные люди занимали ключевые посты по праву крови. Постепенно на парламентских выборах учащались случаи насилия, которые уносили жизни десятков людей ${ }^{93}$. По сути, капитализм и демократия западного образца породили враждебную политическую обстановку. Существовало устоявшееся мнение, что бюрократы расхищают иностранную помощь, а служба безопасности помогает им в этом деле. История знает примеры, когда в случае конфликтов из-за ресурсов или территории миротворческие силы принимали сторону одного клана и снабжали его оружием, разжигая таким образом войну.

В.А. Попова считает: «многопартийность, парламентаризм и другие атрибуты буржуазного общества оказались прикрытием трайбализма, а сам он, по существу, представляет собой не что иное, как использование элементов традиционной культуры в борьбе за власть» ${ }^{94}$.

Колониальный раздел Африки вызвал следующие проблемы. Вновь созданные государства были этнически, лингвистически и конфессионально разнородны ${ }^{95}$. Искусственность государственных границ уже в первые годы независимости вызвала напряженность в отношениях между Сомали и Кенией. В феврале 1964 г. началась эфиопосомалийская война ${ }^{96}$.

В купе с вышеизложенным, эксплуатируемое на протяжении столетий сомалийское население не имело своих средств для независимого развития. Метрополии разорвали многовековые связи между колониями.

Развитие государственности и становление современных политических структур в Сомали тоже приобрело ряд принципиальных особенностей из-за длительного периода колониальной зависимости. Во-первых, эволюция традиционного способа производства прервалась вследствие чужеземного завоевания, ограничения суверенитета и экономиче-

${ }^{89}$ Metz Helen Chapin ed. Somalia: A Country Study. Washington. 1992. P. 164.

${ }^{90}$ Contini P. The Somali Republic: An Experiment in Legal Integration. London. 1969. P. 21.

${ }^{91}$ Andrejewski B. Pastoralism and Politics among Somali // The Journal of African history. Vol. 3. № 3. Cambridge University Press. 1962. P. 517.

${ }_{92}$ Palast Greg. The Best Democracy Money Can Buy: The Truth about Corporate Cons, Globalization and high-finance Fraudsters. London. 2004. P. 33.

${ }^{93}$ Payton G. The Somali Coup of 1969. The Case for Soviet Complicity // The Journal of Modern African Studies. Vol. 18. № 3. Cambridge University Press. 1980. P. 501.

${ }^{94}$ Tareke G. The Ethiopia-Somalia War of 1977 Revisited // International Journal of African Historical Studies. - 2000. Vol. 33. № 3. P. 644.

${ }^{95}$ Breen B. A Little Bit of Hope: Australian Force Somalia. Canberra. 1998. P. 7.

${ }^{96}$ Lewis I.M. Understanding Somalia and Somaliland. London. 2008. P. 29. 
ской экспансии. В результате формировавшиеся столетиями принципы производства и уклад жизни постепенно ушли на второй план, в жизнь вводился навязанный капиталистами формат. В результате было блокировано общение и взаимодействие с другими африканскими обществами. Развитие сомалийского народа, по существу, было заторможено и даже в некоторой степени повернуто вспять.

С другой стороны, создание новых форм государственности не означало установления всеобщего контроля. В этом особенность традиционных экономик, которые живут замкнутой жизнью закрытого общества. Именно этим объясняется появление многочисленных сепаратистских движений, чей разрушительный потенциал до сих пор неоколониализм пытается использовать в своих корыстных интересах.

В начале 60-х гг. на смену навязанному африканцам капитализму пришел социализм с африканским лицом. В число его задач входили:

- культивация африканских традиций;

- обмен опытом со странами Запада и Востока;

- построение единого общества, невзирая на классовую рознь;

- формирование массовой политической партии.

Нормы морали следовало брать из религии, которая составила культурный базис страны.

Однако Сомали, как и другие страны Африки, находившиеся в составе колониальных империй, прошли через процедуру принудительной этнизации населения, когда каждому племени или клану отводилась своя территория с четко очерченными границами. Общности, которые не удавалось связать с какой-либо территорией, игнорировались колониальными властями. В результате африканский народ связал борьбу за создание государства-нации с борьбой против колонизаторов. Это наиболее ярко видно на примере идеи создания «Великого Сомали», лелеянной С. Барре.

До колонизации Сомали решения всех вопросов в сомалийском обществе принимались после длительного обсуждения советом старейшин. Назначаемые колонизаторами вожди племен были удобными марионетками для управления.

Но кланы живут и кочуют не только в Сомали, но и на территории соседних государств. Поэтому власти метрополий так и не смогли найти баланс между интересами разных сторон. Такая ситуация дает возможность предполагать, что в Сомали возможно образовать конфедеративное государство.

Другая проблема состоит в большом количестве участников переговорного процесса. Отсюда клановый подход к разрешению конфликта не является абсолютно верным. Получается, что навязывание норм управления страной извне не дает долгосрочного эффекта. Чтобы сгладить основные противоречия, необходимо найти точки соприкосновения между политиками и лидерами политических группировок.

Вопрос об урегулировании сомалийского кризиса остается открытым, так как в стране наблюдается высокий уровень бедности, социального неравенства, этнических противоречий, неэффективности государственных структур. В такой ситуации построение государства-нации воспринимается как искусственное насаждение чужеродных устоев, что может привести к эскалации конфликта. Эту проблему мировое сообщение должно рассматривать стратегически. Предыдущие попытки разрешения этой ситуации путем миростроительства сопровождались военной интервенцией и заменой одного недееспособного института другим. «В итоге государство само по себе должно выработать свою уникальную стратегию преодоления кризиса правления, которая учитывала бы реальную легитимность и, следовательно, способность государства эффективно управлять» ${ }^{97}$.

${ }^{97}$ Dorff R. Failed States After 9/11: What Did We Know and What Have We Learned? // «International Studies Perspectives». No 6. P. 30. 


\section{Список литературы}

1. Africa: Forecasts. Standard Bank, Johannesburg, 2010.

2. Andrejewski B. Pastoralism and Politics among Somali // The Journal of African history. Vol. 3. No. 3. Cambridge University Press, 1962.

3. Breen B. A Little Bit of Hope: Australian Force Somalia. Canberra. 1998.

4. Central Bank of Somalia Annual Report. Mogadishu. 2012.

5. Contini P. The Somali Republic: An Experiment in Legal Integration. London. 1969.

6. Dorff R. Failed States After 9/11: What Did We Know and What Have We Learned? // International Studies Perspectives. No 6. 2005.

7. Dubner B.H. On the definition of the crime of sea piracy revisited: Customary vs. treaty law and the jurisdictional implications thereof // The Journal of Maritime Law and Commerce. Vol. 42. No. 1. 2011.

8. Gauci G. Piracy and its legal problems: With specific reference to the English law and marine insurance // Journal of Maritime Law and Commerce. Vol. 41. No. 4. 2010.

9. Grubeck N. Civilian harm in Somalia: Creating an Appropriate Response civilians in armed conflict series // Campaign for Innocent Victims in Conflict (CIVIC). 2011.

10. Hassan F.A. Somali Clans are the Key // New African. T. 331 (June). No. 20.

11. Jeffrey R.S. An efficient solution in a time of economic hardship: The right to keep and bear arms in self-defense against pirates // Journal of Maritime Law and Commerce. Vol. 41. No. 4. 2010.

12. Kontorovich E., Art S. An empirical examination of universal jurisdiction' for piracy // American-Journal of International Law. Vol. 104. No. 3. 2010.

13. Lewis I.M. Understanding Somalia and Somaliland / London. 2008.

14. Metz Helen Chapin ed. Somalia: A Country Study / Washington. 1992.

15. Murphy M.N. Small boats, weak states, dirty money: piracy \& maritime terrorism in the modern world. London. 2010.

16. Palast G. The Best Democracy Money Can Buy: The Truth about Corporate Cons, Globalization and high-finance Fraudsters. London. 2004.

17. Patrick S. Weak States and Global Threats: Fact or Fiction? // The Washington Quarterly. Vol. 2, No. 29. 2006.

18. Payton G. The Somali Coup of 1969. The Case for Soviet Complicity // The Journal of Modern African Studies. Vol. 18. No. 3. Cambridge University Press. 1980.

19. Population Estimation Survey. For the 18 Pre-War Regions of Somalia. United Nations Population Fund, Somalia Country Office. UNON, Publishing Services Section, Nairobi, ISO 14001: 2004-certified. October 2014.

Press. 2004.

20. Rotberg R. When States Fail: Causes and Consequences. Princeton, NJ: Princeton University

21. Talentino A.K. The Two Faces of Nation-Building: Developing Function and Identity // Cambridge Review of International Affairs. Vol. 17. No. 3. 2004.

22. Tarek G. The Ethiopia-Somalia War of 1977 Revisited // International Journal of African Historical Studies. Vol. 33. № 3. 2010.

23. The Thomson Reuters Foundation. The world's most dangerous countries for women. 4 May, 2018.

24. Woodward P. Somalia and Sudan: A Tale of Two Peace Processes // The Round Table. Vol. 93. No. 375. 2014.

\section{References}

1. Africa: Forecasts. Standard Bank, Johannesburg, 2010.

2. Andrejewski B. Pastoralism and Politics among Somali // The Journal of African history. Vol. 3. No. 3. Cambridge University Press, 1962.

3. Breen B. A Little Bit of Hope: Australian Force Somalia. Canberra. 1998.

4. Central Bank of Somalia Annual Report. Mogadishu. 2012.

5. Contini P. The Somali Republic: An Experiment in Legal Integration. London. 1969.

6. Dorff R. Failed States After 9/11: What Did We Know and What Have We Learned? // International Studies Perspectives. No 6. 2005. 
7. Dubner B.H. On the definition of the crime of sea piracy revisited: Customary vs. treaty law and the jurisdictional implications thereof // The Journal of Maritime Law and Commerce. Vol. 42. No. 1. 2011.

8. Gauci G. Piracy and its legal problems: With specific reference to the English law and marine insurance // Journal of Maritime Law and Commerce. Vol. 41. No. 4. 2010.

9. Grubeck N. Civilian harm in Somalia: Creating an Appropriate Response civilians in armed conflict series // Campaign for Innocent Victims in Conflict (CIVIC). 2011.

10. Hassan F.A. Somali Clans are the Key // New African. T. 331 (June). No. 20.

11. Jeffrey R.S. An efficient solution in a time of economic hardship: The right to keep and bear arms in self-defense against pirates // Journal of Maritime Law and Commerce. Vol. 41. No. 4. 2010.

12. Kontorovich E., Art S. An empirical examination of universal jurisdiction' for piracy // American-Journal of International Law. Vol. 104. No. 3. 2010.

13. Lewis I.M. Understanding Somalia and Somaliland / London. 2008.

14. Metz Helen Chapin ed. Somalia: A Country Study / Washington. 1992.

15. Murphy M.N. Small boats, weak states, dirty money: piracy \& maritime terrorism in the modern world. London. 2010.

16. Palast G. The Best Democracy Money Can Buy: The Truth about Corporate Cons, Globalization and high-finance Fraudsters. London. 2004.

17. Patrick S. Weak States and Global Threats: Fact or Fiction? // The Washington Quarterly. Vol. 2, No. 29. 2006.

18. Payton G. The Somali Coup of 1969. The Case for Soviet Complicity // The Journal of Modern African Studies. Vol. 18. No. 3. Cambridge University Press. 1980.

19. Population Estimation Survey. For the 18 Pre-War Regions of Somalia. United Nations Population Fund, Somalia Country Office. UNON, Publishing Services Section, Nairobi, ISO 14001: 2004-certified. October 2014.

20. Rotberg R. When States Fail: Causes and Consequences. Princeton, NJ: Princeton University Press. 2004.

21. Talentino A.K. The Two Faces of Nation-Building: Developing Function and Identity // Cambridge Review of International Affairs. Vol. 17. No. 3. 2004.

22. Tarek G. The Ethiopia-Somalia War of 1977 Revisited // International Journal of African Historical Studies. Vol. 33. № 3. 2010.

23. The Thomson Reuters Foundation. The world's most dangerous countries for women. 4 May, 2018.

24. Woodward P. Somalia and Sudan: A Tale of Two Peace Processes // The Round Table. Vol. 93. No. 375. 2014.

\section{ИНФОРМАЦИЯ ОБ АВТОРЕ}

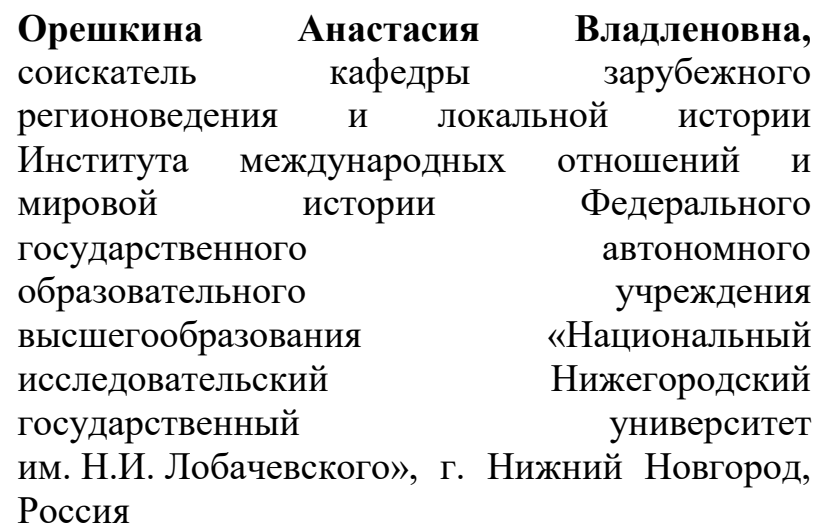

\section{INFORMATION ABOUT THE AUTHOR}

Anastasia V. Oreshkina, applicant at the department of foreign regional studies and local history of the Institute of Foreign Relations and worlds history of the Federal state autonomous educational body of the higher education «National scientific Nizhegorodsky state university named after N.I. Lobachevskogo», Nizhniy Novgorod, Russia 